\title{
REACTIONS OF HALOGEN ATOMS
}

\author{
P. Goldfinger \\ Service de Chimie Physique I, Université Libre de Bruxelles, Belgique
}

\section{INTRODUCTION}

It is usual to distinguish between two general methods for investigating gas phase atomic and free radical reactions.

High concentrations of atoms or free radicals may be produced in electric discharges, at very high temperatures (shock waves), by high light intensities (flash photolysis), etc. Atoms or free radicals may be more-or-less directly observed by optical spectroscopy, mass spectrometry or other methods; alternatively, they may be trapped in matrices at low temperatures and detected by different methods, such as electron spin resonance.

The more classical method of investigation, initiated probably in the first decades of this century by Bodenstein and his students, consists in studying the mechanism of thermal and photochemical reactions which can usually be considered as slow reactions. They proceed at rates corresponding to halflives of the order of several minutes.

In the case of halogen atom reactions a considerable effort has been made in the last decade at the Photochemistry Laboratory of the Universite Libre de Bruxelles, in the laboratories of Professors Dainton ${ }^{1}$, Le Roy ${ }^{2}$, TrotmanDickenson and $\mathrm{Knox}^{3}$ and others using this classical method. Important progress has been made as regards improvement of the accuracy of the analysis of such systems and, in many cases, this has enabled unambiguous reaction mechanisms and, finally, precise values of rate constants to be determined.

Attempts have been made by Trotman-Dickenson, Knox ${ }^{3}$, Pitzer ${ }^{4}$ and Johnston, to discuss these reaction rates in terms of activated complex theory. Recently Johnston ${ }^{5}$ has made a comprehensive study of the possibilities and limitations of this method as applied to these reactions.

In this paper, the progress which has been made in the methods of analysis of complex reactions will be described first. Subsequently, the results will be presented and a few questions mentioned which have not yet been settled. Finally, the significance of the results will be discussed in terms of activated complex theory.

\section{ANALYSIS OF COMPLEX REAGTIONS}

In the early days the approach to the analysis of any reaction mechanism was necessarily purely empirical. At present we know a sufficient number of "types" of elementary reactions and reactive species so that it is often possible to put forward a very reasonable mechanism. Thus, for the photochlorination of tetrachloroethylene and pentachloroethane we may envisage:

$$
\begin{gathered}
\mathrm{Cl}+\mathrm{Cl}_{2} \mathrm{Cl}_{4} \longrightarrow h \nu \longrightarrow 2 \mathrm{Cl} \\
\mathrm{Cl}_{2} \mathrm{Cl}_{5} \quad(2) \mathrm{Cl}+\mathrm{C}_{2} \mathrm{HCl}_{5} \longrightarrow \mathrm{C}_{2} \mathrm{Cl}_{5}+\mathrm{HCl} \\
\mathrm{C}_{2} \mathrm{Cl}_{5}+\mathrm{Cl}_{2} \longrightarrow \mathrm{C}_{2} \mathrm{Cl}_{6}+\mathrm{Cl}
\end{gathered}
$$




$$
\begin{aligned}
\mathrm{C}_{2} \mathrm{Cl}_{5} \longrightarrow \mathrm{C}_{2} \mathrm{Cl}_{4}+\mathrm{Cl} \quad(4) \mathrm{C}_{2} \mathrm{Cl}_{5}+\mathrm{HCl} \longrightarrow \mathrm{C}_{2} \mathrm{Cl}_{5} \mathrm{H}+\mathrm{Cl} \\
\mathrm{Cl}_{2} \mathrm{Cl}_{6}+\mathrm{Cl} \longrightarrow \mathrm{C}_{2} \mathrm{Cl}_{5}+\mathrm{Cl}_{2} \\
\mathrm{Cl}+\mathrm{Cl}+\mathrm{M} \longrightarrow \mathrm{Cl}_{2}+\mathrm{M} \\
\left.\mathrm{Cl}+\mathrm{C}_{2} \mathrm{Cl}_{5} \longrightarrow \mathrm{C}_{2} \mathrm{Cl}_{6} \text { (or } \mathrm{C}_{2} \mathrm{Cl}_{4}+\mathrm{Cl}_{2}\right) \\
\left.\mathrm{C}_{2} \mathrm{Cl}_{5}+\mathrm{C}_{2} \mathrm{Cl}_{5} \longrightarrow \mathrm{C}_{2} \mathrm{Cl}_{6}+\mathrm{C}_{2} \mathrm{Cl}_{4} \text { (or } \mathrm{C}_{4} \mathrm{Cl}_{10}\right)
\end{aligned}
$$

There is no doubt that light of 4358 or $3660 \AA$ dissociates molecular chlorine into atoms. It is then assumed that a chlorine atom adds to a double bond or abstracts a hydrogen atom, and that a free radical is formed. Then, all reactions between all species present can be said to incorporate the original reagents, the atom and the free radical.

Such a mechanism permits one to make a limited number of tests and also to plan them in the most suitable manner. Even though it may appear obvious, it is not superfluous to emphasize the necessity of examining the possibility of alternative mechanisms and reaction steps. General types of mechanisms have been developed by Goldfinger, Letort and Niclause ${ }^{6}$ and have been extended by other authors ${ }^{7}$. These show clearly the ambiguity of tests if restricted in number. Some cases will be discussed later.

According to the conditions discussed by Benson ${ }^{8}$, Adam, Dusoleil and Goldfinger ${ }^{9}$, the so-called steady state approximation can be used here and leads, for the reaction rate, to the equations:

$$
\begin{aligned}
& -\mathrm{d}\left(\mathrm{Cl}_{2}\right) / \mathrm{d} t=I_{2}^{\frac{1}{2}} k_{3}\left(\mathrm{Cl}_{2}\right)\left\{k_{8}+k_{7}\left[k_{4}+k_{3}\left(\mathrm{Cl}_{2}\right)\right] /\left[k_{2}\left(\mathrm{C}_{2} \mathrm{Cl}_{4}\right)+k_{2}^{\prime}\left(\mathrm{C}_{2} \mathrm{HCl}_{5}\right)\right]\right\}^{-\frac{1}{2}} \\
& -\frac{\mathrm{d} p}{\mathrm{~d} t}=\frac{I_{2}^{\frac{1}{2}}\left\{k_{4}-k_{2}\left(\mathrm{C}_{2} \mathrm{Cl}_{4}\right)\left[k_{4}+k_{3}\left(\mathrm{Cl}_{2}\right)\right] /\left[k_{2}\left(\mathrm{C}_{2} \mathrm{Cl}_{4}\right)+k_{2}^{\prime}\left(\mathrm{C}_{2} \mathrm{HCl}_{5}\right)\right]\right\}}{\left\{k_{8}+k_{7}\left[k_{4}+k_{3}\left(\mathrm{Cl}_{2}\right)\right] /\left[k_{2}\left(\mathrm{C}_{2} \mathrm{Cl}_{4}\right)+k_{2}^{\prime}\left(\mathrm{C}_{2} \mathrm{HCl}_{5}\right)\right]\right\}^{\frac{1}{2}}}
\end{aligned}
$$

Even though some simplifications, which had been explained in previous papers have been made already, such as neglecting reaction steps $\left(4^{\prime}\right),(5)$ and (6), these equations are still rather complicated. One further simplification may be achieved by working in the presence of only one reagent, i.e. either tetrachloroethylene or pentachloroethane. It is then useful to write the rate equations in the form of inverse squares such as:

$$
\frac{I_{\mathrm{a}}\left(\mathrm{Cl}_{2}\right)}{v^{2}}=\frac{k_{8}}{k_{3}^{2}}+\frac{k_{7}\left[k_{4}+k_{3}\left(\mathrm{Cl}_{2}\right)\right]}{k_{3}^{2} k_{2}\left(\mathrm{G}_{2} \mathrm{Gl}_{4}\right)}
$$

This form of rate equation is particularly favourable for checking the assumed properties of the mechanism and to measure combinations of rate constants by varying concentrations or concentration ratios, while others are kept constant. By performing this at different temperatures combinations of frequency factors and activation energies are obtained. Finally, experiments in intermittent light, treated in a similar way, yield individual values of rate constants, frequency factors and activation energies.

Actually, the interest in the tretrachloroethylene -pentachloroethane system resides in the fact that the 8 rate determining constants are obtained by measuring about 15 to 20 experimental parameters; consequently, one can obtain an impressive number of cross checks for the mechanism. 


\section{REACTIONS OF HALOGEN ATOMS}

These cross checks and the effort of increasing the accuracy of the measurements led to a number of observations.

\section{Constant and variable reaction orders}

In some instances, the plot of the logarithm of reaction rate $v$. log of concentration ratios ${ }^{10}$ of the appropriate reagent gives a straight line whose
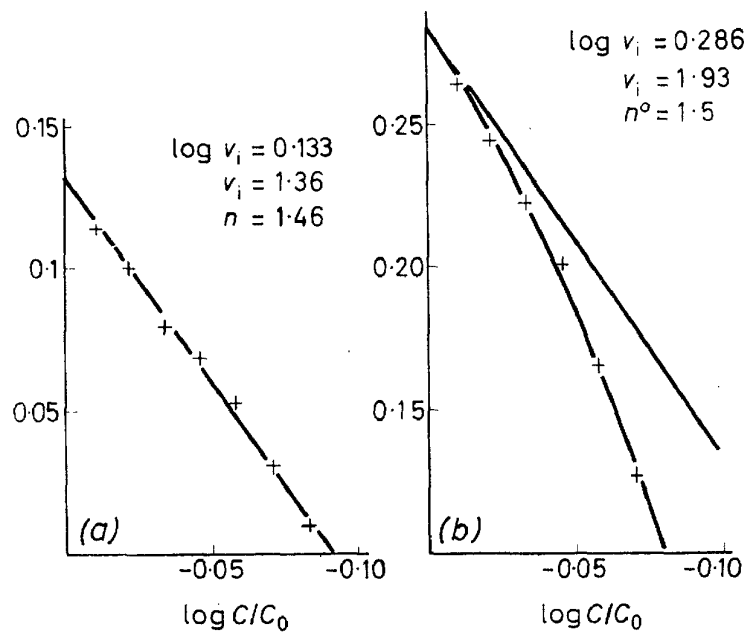

Figure 1. Logarithmic plot of the rate of photochlorination of a mixture: $\mathrm{Cl}_{2}=61.5 \mathrm{~mm}$; $\mathrm{C}_{2} \mathrm{Cl}_{4}=30.1 \mathrm{~mm} ; \mathrm{CH}_{4}=29.7 \mathrm{~mm}$ at $360.5^{\circ} \mathrm{K}$, v. concentration of chlorine; (a) constant reaction order with respect to the rate $\mathrm{C}_{2} \mathrm{Cl}_{4}+\mathrm{Cl}_{2} \longrightarrow \mathrm{Cl}_{2} \mathrm{Cl}_{6}$; (b) increasing reaction order with respect to $\mathrm{CH}_{4}+\mathrm{Cl}_{2} \longrightarrow \mathrm{CH}_{3} \mathrm{Cl}+\mathrm{HCl}$

slope (the reaction order) is, within an accuracy of about 1 to 2 per cent, an integer multiple of one-half. This is the case if, for instance in an equation

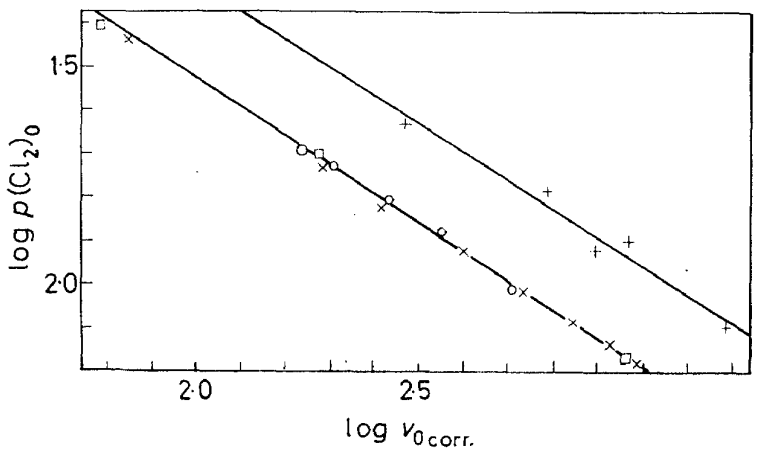

Figure 2. Logarithmic plot of the " initial rate" of photochlorination of trichloroethylene $v$. initial pressure of chlorine at 363.8 and $418.6^{\circ} \mathrm{K}$; rates are in $\mathrm{mm}$ per sec per (einstein $\left.1^{-1} \mathrm{sec}^{-1}\right)^{\frac{1}{2}}$ and pressures in $\mathrm{mm}$; the reaction order, obtained by least squares, is 1.52 and $1 \cdot 54$

of the form of (iii), the second term is negligible or if it depends only on the ratio of chlorine to tetrachloroethylene and if this ratio is practically 


\section{P. GOLDFINGER}

equal to one. In other cases, the reaction order may increase or decrease as the reaction proceeds. Examples of constant and variable reaction orders are given in Figure 1.

This shows, as already emphasized by Letort ${ }^{\mathbf{1 0}}$, that great care must be taken in extrapolating to " initial rates", which are then inserted in equation (iii) or plotted $v$. initial concentrations on a logarithmic scale for determining reaction orders ${ }^{10}$, as in Figure 2. In the case of constant reaction orders integration methods may be used; they obviously lead to misinterpretations as the complexity of reaction order increases. Also determination of " initial slopes" of concentration $v$. time plots, without checking the logarithmic rate $v$. concentration plot, can easily be misleading.

\section{Induction periods and auto-inhibition}

A number of years ago Adam and Goldfinger ${ }^{11}$ had obtained initial rates for this reaction:

$$
\mathrm{C}_{2} \mathrm{HCl}_{5} \longrightarrow \mathrm{C}_{2} \mathrm{Cl}_{4}+\mathrm{HCl}
$$

and these initial rates seemed to correspond nicely to a one-half order with respect to pentachloroethane as is expected from equation (ii) if the negative term is neglected and only the chain breaking step (7) is considered. The recent re-investigation showed, however, the result given in Figure 3. A

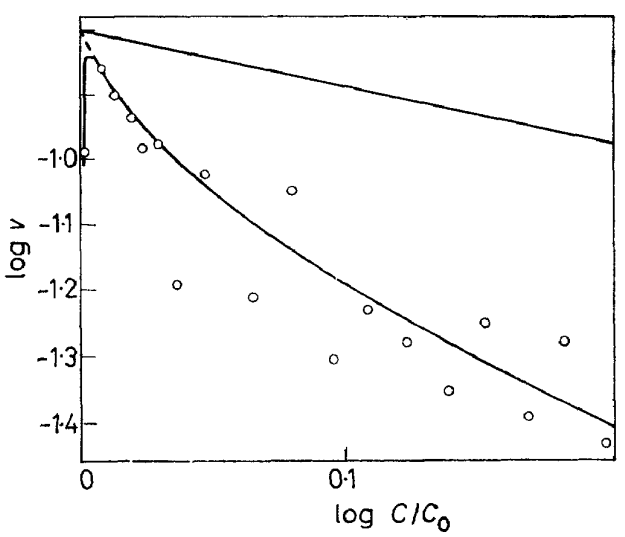

Figure 3. Logarithmic plot of rate $v$. pentachloroethane pressure for the dehydrochlorination of pentachloroethane: $\mathrm{Cl}_{2}=13.0 \mathrm{~mm} ; \mathrm{C}_{2} \mathrm{HCl}_{5}=48.3 \mathrm{~mm} ; \quad I_{\mathrm{a}}=10^{-9.85}$ einstein 1. ${ }^{-1} \mathrm{sec}^{-1}$ at $473^{\circ} \mathrm{K}$ (Reproduced by permission of the Council of the Faraday Society from Trans. Faraday Soc. 57, 2218 (1962))

true induction period is first observed in agreement with what can be calculated using the method described earlier ${ }^{9}$ : the relevant rate constants are now known. Figure 3 further shows that before the steady state rate has been reached, an " inhibiting" action appears due to the negative term of equation (ii). At present, it is possible to calculate the "rate without the negative term": this gives the straight line of slope $1 / 2$ shown in Figure 3. Furthermore, the complete course of the reaction may be calculated including an estimate of the induction period, which is the full curve, in reasonably good agreement with the experimental results. It is necessary to point out 


\section{REACTIONS OF HALOGEN ATOMS}

that the apparent scatter of these points is due to the fact that individual values of $\Delta p / \Delta t$ have been taken over very short time intervals and small pressure changes and that on purpose no "smooth curve" has been drawn through these points.

In fact a posteriori a smooth curve can now be drawn and it is difficult to resist the temptation of insisting again on an obvious remark: a smooth curve can only be drawn if its shape is known. Of course it must be understood that complex kinetics, such as those shown in Figure 3 can be used as a confirmation of measured constants but cannot, by themselves, yield accurate values; they can also be used as a confirmation of a mechanism but by no means as a basis for developing one.

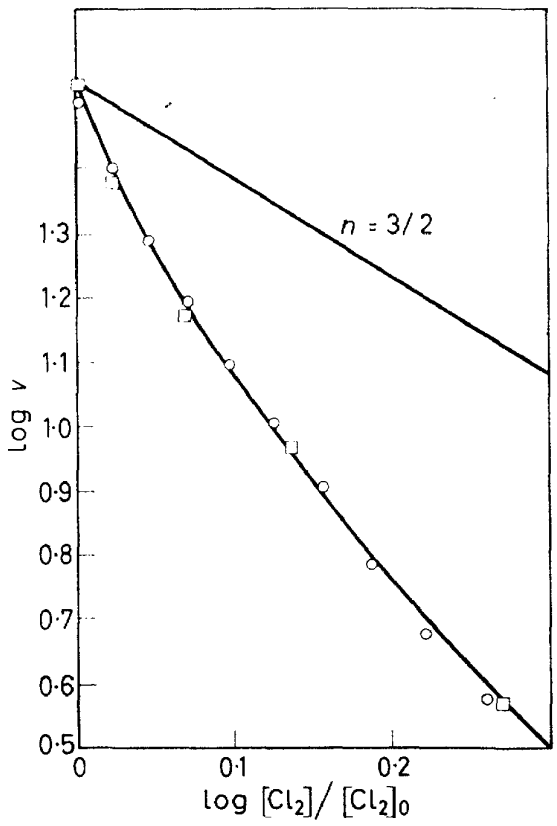

Figure 4. Logarithmic plot of the rate of photochlorination of methyl chloride $v$. chlorine pressure; initial pressures of both components $30 \cdot 3 \mathrm{~mm}$, temperature $389^{\circ} \mathrm{K}, I_{0}=10^{-8}$ einstein $10^{-1} \sec ^{-1}$ (Reproduced by permission of Verlag Chemie GmbH from Chem. Ber. 93, $3024(1960))$

A case of auto-inhibition occurs also in the photochlorination of methane, methyl chloride and methylene chloride. As soon as small amounts of reaction products, methyl chloride, dichloromethane and chloroform respectively, are formed, they in turn react and a systematic development of the reaction scheme given above leads to the rate equation ${ }^{12}$ :

$\left(v_{\mathrm{A}}^{*}+v_{\mathrm{B}}^{*}+v_{\mathrm{C}}^{*}+\ldots\right) / v_{\mathrm{A}}=$

$=\left(1+\phi_{\mathrm{B}} / \phi_{\mathrm{A}}+\phi_{\mathrm{C}} / \phi_{\mathrm{A}}+\ldots\right) /\left[1+\left(v_{\mathrm{A}} \phi_{\mathrm{B}} / v_{\mathrm{B}} \phi_{\mathrm{A}}\right)^{2}+\left(v_{\mathrm{A}} \phi_{\mathrm{C}} / v_{\mathrm{C}} \phi_{\mathrm{A}}\right)^{2}+\ldots\right]^{\frac{1}{2}}$

Here $v_{\mathrm{A}} \ldots$ are the reaction rates of the pure reagents $\mathrm{A} \ldots, v_{\mathrm{A}}^{*} \ldots$ the rates of the same components in the presence of the others and $\phi_{\mathrm{B}} / \phi_{\mathrm{A}}$ the relative rates of formation of free radicals from $\mathrm{B}, \mathrm{A}$, etc., respectively, i.e. the rates of 


\section{P. GOLDFINGER}

hydrogen abstraction by chlorine atoms from methyl chloride, dichloromethane and chloroform compared to the rate for methane. Equation (iv) measures the relative inhibition compared to an idealized reaction of a pure component. By studying these substances in the order chloroform, dichloromethane, methyl chloride and methane, all the terms in equations, such as (iv), could be determined. Figure 4 shows the experimental points for methyl chloride in the logarithmic form; the $n=3 / 2$ line is the "ideal rate" obtained from the " experimental curve" by means of equation (iv).

\section{The Draper effect}

A correction which is quite important results from the insufficient dissipation of the reaction heat. Figure 5 shows the chlorine concentration and the pressure $v$. time curve for the photochlorination of trichloroethylene. The true induction period, in this case, is too short to be observed and, therefore, the chlorine concentration seems to decrease monotonously. The pressure, however, increases first, and only after about 20 seconds follows a course parallel to the chlorine curve. This effect was observed 120 years ago in the $\mathrm{H}_{2}+\mathrm{Cl}_{2}$ reaction by Draper ${ }^{13}$ and explained quantitatively by Benson ${ }^{14}$ and Wilson ${ }^{15}$. Its importance for photochlorination reactions has been

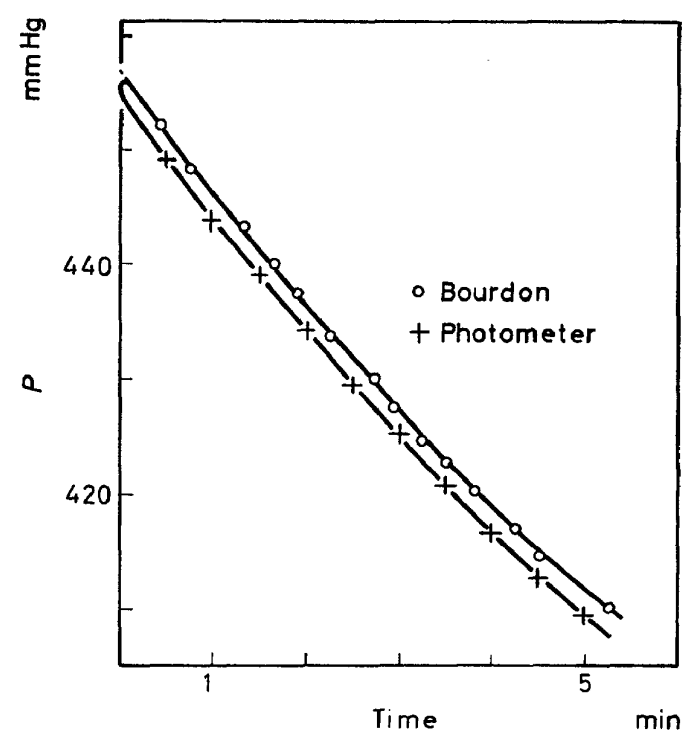

Figure 5. Total pressure (bourdon gauge) and chlorine partial pressure (photometer) as a function of time for the photochlorination of trichloroethylene at $364 \cdot 1^{\circ} \mathrm{K}$, in the presence of: $\mathrm{CO}_{2}=253.1 \mathrm{~mm}$ as inert gas; $\mathrm{C}_{2} \mathrm{HCl}_{3}=49.0 \mathrm{~mm} ; \mathrm{Cl}_{2}=152.1 \mathrm{~mm}$; the photometer curve has been shifted upwards by $49 \cdot 0+253 \cdot 1=302 \cdot 1 \mathrm{~mm}$, which should bring it in superposition with the bourdon curve

discussed by Goldfinger et al. ${ }^{16}$. It can result in an increase in temperature of several degrees and gives rise to apparent pressure and temperature dependence curves which are inaccurate. In fact, every variation of a parameter, which increases the rate, leads to an increased temperature effect and hence to an exaggerated rate increase. Due corrections bring 


\section{REACTIONS OF HALOGEN ATOMS}

the two curves of Figure 5 into superposition and often eliminate apparent inconsistencies ${ }^{16}$.

\section{RESULTS AND DISGUSSION}

Initial rates may be plotted according to equation (iii) and permit one to determine the contribution of different chain-breaking steps to the mechanism as shown for example in Figures 6 and 7. From these plots combinations
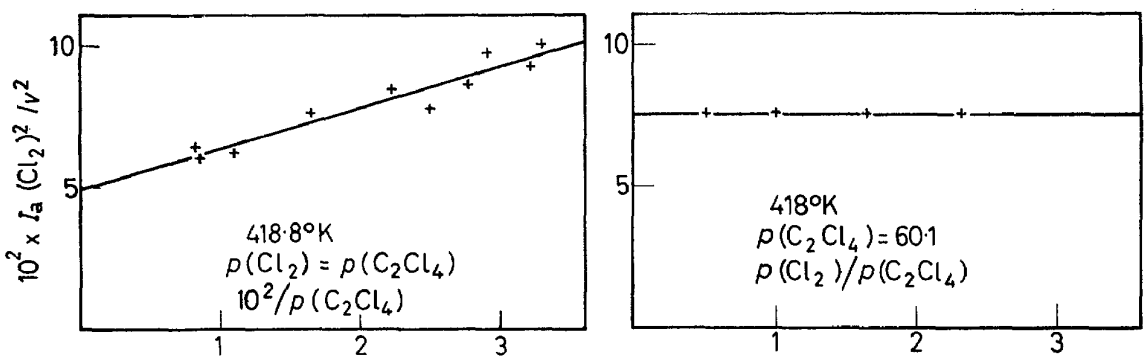

Figure 6. Photochlorination of tetrachloroethylene plotted according to equation (iii) (Reproduced by permission of the Council of the Faraday Society from Trans. Faraday Soc. 57, $2200(1961)$ )

of rate constants are obtained and from their temperature dependence, frequency factors and activation energies are calculated. Experiments

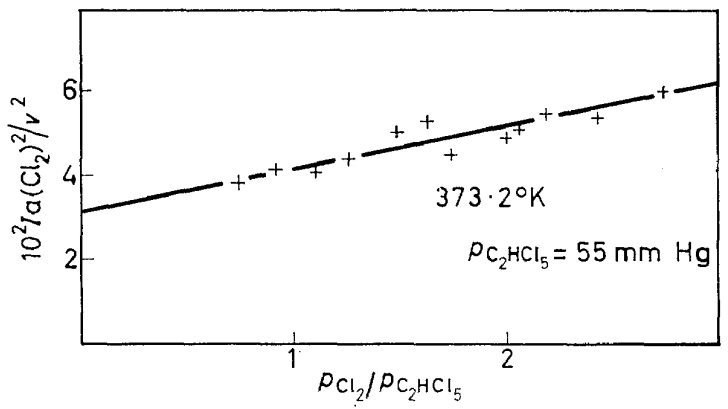

Figure 7. Photochlorination of pentachloroethane plotted according to equation (iii)

with intermittent light are treated in a similar way. The magnitude measured is the lifetime of a reaction chain:

$$
\tau_{0}=(1+\alpha+\beta+\ldots) / 2 I_{\mathrm{a}}^{\frac{1}{2}} k_{\mathrm{t}}^{\frac{1}{2}}
$$

Here $\alpha, \beta$ are ratios of steady state concentrations of chain-carrying radicals; in the case of the assumed mechanism with 2 chain carriers $\beta=0$, and $k_{\mathrm{t}}=$ $k_{8}+k_{7} \alpha+\ldots$. Combining (v) with the rate equation for steady light, which can be put into the simple form:

yields

$$
v_{\mathrm{s}}=I_{\mathrm{a}}^{\frac{1}{\mathrm{~s}}} k_{3}\left(\mathrm{Cl}_{2}\right) / k_{\mathrm{t}}^{\frac{1}{2}}
$$

$$
2 I_{\mathrm{a}} \tau_{0}\left(\mathrm{Cl}_{2}\right) / v_{\mathrm{s}}=(1+\alpha+\beta \ldots) / k_{3}
$$




\section{P. GOLDFINGER}

A plot of the left-hand side of (vii) $v \cdot 1 /\left(\mathrm{C}_{2} \mathrm{Cl}_{4}\right)$, which is the expected concentration dependence of $\alpha$, does not show a measurable slope (Figure 8).

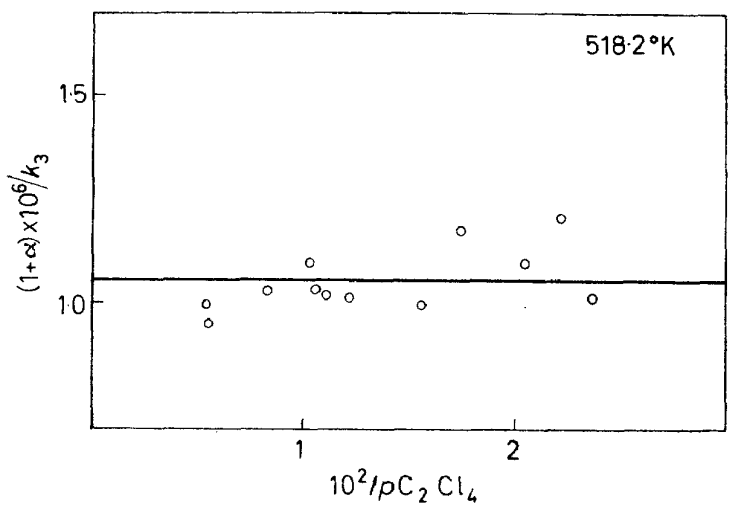

Figure 8. Intermittent light experiment with tetrachloroethylene plotted according to equation (vii) (Reproduced by permission of the Council of the Faraday Society from Trans. Faraday Soc. 57, 2204 (1961))

This permits one thus to determine $k_{3}$ but not $\alpha=(\mathrm{Cl}) /\left(\mathrm{C}_{2} \mathrm{Cl}_{5}\right)$. In this case the chlorine atom concentration is too low to be measured directly, especially as there is always a relatively high experimental error in intermittent light experiments. In the case of the phosgene photosynthesis, Burns and Dainton ${ }^{17}$ succeeded in measuring the ratio of $(\mathrm{Cl}) /(\mathrm{COCl})$, which, in that case, is actually of the order of unity.

Combining these results and taking into account competition experiments $\mathrm{s}^{3,18}$, tables comprising about 100 elementary rate constants could be calculated ${ }^{3,12,18}$.

(a) The first question which arises now is whether the rate constants actually belong to those reaction steps as given above. Perhaps all these results could be represented by another mechanism and then the reaction steps corresponding to $k_{2} \ldots k_{8}$ would be different.

It may certainly be safely accepted that chlorine is dissociated into atoms. However, an alternative to the assumption that a chlorine atom adds to a double bond or abstracts a hydrogen atom, is that of the formation of a trichloryl radical, and a reaction sequence based on this species had been put forward by Rollefson ${ }^{19}$. In fact, many features presented here could be easily understood by a Rollefson-type mechanism, others, in particular photosensitized reactions of the type

$$
\mathrm{C}_{2} \mathrm{HCl}_{5} \longrightarrow \mathrm{C}_{2} \mathrm{Cl}_{4}+\mathrm{HCl}
$$

could raise some difficulties. However, as mentioned, these reactions have often a rather complicated mechanism and, therefore, a clear cut answer may involve risks.

There is further evidence that entities like the trichloryl radical may be quite stable; quite convincing evidence ${ }^{20}$ is now available for the existence of tri-iodyl and tribromyl radicals. 


\section{REACTIONS OF HALOGEN ATOMS}

Burns and Dainton ${ }^{17}$ tried to examine this question in the case of the $\mathrm{CO}+\mathrm{Cl}_{2}$ reaction using an equation equivalent to (vii) and showed that a term $\alpha=(\mathrm{Cl}) /(\mathrm{COCl})$ is of the order of one, whereas a term $\beta=\left(\mathrm{Cl}_{3}\right) /$ $(\mathrm{COCl})$ or $\left(\mathrm{Cl}_{3}\right) /(\mathrm{Cl})$ is negligible. However, the sensitivity of this method is not very great and the best one can say is that the value of $\beta$ is not more than a few per cent. However, the most important fact which can be deduced is that this does by no means exclude the trichloryl radical as a chain carrier. Thus, in the mechanism assumed here, $(\mathrm{Cl}) /\left(\mathrm{C}_{2} \mathrm{Cl}_{5}\right)$ varies between $10^{-3}$ and $5 \times 10^{-2}$.

There is, however, a straightforward method which has been used by Chiltz et al. ${ }^{7}$ and which was also suggested a number of years ago by Noyes and Leighton ${ }^{21}$. It is easy to show that a term of the form $k_{8} / k_{3}^{2}$ in equation (iii) should occur also in a Rollefson-type mechanism. Here, this term means $k_{\mathrm{R}+\mathrm{R}} / k_{\mathrm{R}+\mathrm{Cl}_{2}}^{2}$; in a Rollefson-type mechanism it means $k_{\mathrm{Cl}+\mathrm{Cl}} / k_{\mathrm{Cl}+\mathrm{Cl}_{2}}$. So in the first case the magnitude of this term should depend on the nature of the radical and, therefore, on the reagent, in the second it should be independent of it, since it contains only properties of the chlorine atom and chlorine molecule; further, the chlorine atom recombination constant $k_{\mathrm{Cl}+\mathrm{Cl}}$ should depend on total pressure.

Accurate analysis of equation (iii) permits one to determine $k_{8} / k_{3}^{2}$ ratios for numerous chlorinations and these vary by a factor of several thousand from methane to tetrachloroethylene. Identical values are, however, found for tetrachloroethylene and pentachloroethane since they both give the pentachloroethyl radical. Again, trichloroethylene yields the same value as 1,1,2,2-tetrachloroethane.

It is probably necessary to emphasize here that the discussion of the Rollefson mechanism may be rather of methodological importance than of practical interest. Nevertheless, it is important to examine whether purely kinetic considerations can give a clear-cut decision as to a reaction mechanism and to discuss the validity and the choice of adequate kinetic arguments.

One could inquire further whether part of the products are formed with the trichloryl radical as an intermediate. Even though quantitative calculations are not easy and do not seem to have been made, it seems safe to estimate that, if any, certainly not more than 1 per cent of the products are formed by reactions of the trichloryl radical. Since the accuracy of measured rate constants, and especially elementary constants, is only in a few favourable cases of the order of perhaps 5 to 10 per cent, this answer may be considered as acceptable as long as no very great improvements can be made in experimental techniques. Finally, it can be shown that no alternative third atomic or free radical mechanism is possible for these reactions ${ }^{7}$.

(b) Next, the role of other possible reaction steps must be considered. At Brussels, in conditioned Pyrex reaction cells, as long as the total pressure was higher than 35 to $50 \mathrm{~mm} \mathrm{Hg}$, no wall reactions could be observed. This shows that the reactive entities (mainly free radicals) survive about $10^{5}$ wall collisions under these circumstances. Ayscough, Dainton and co-workers ${ }^{22}$ seem however to have observed chlorine atom recombination on the walls, when working at several hundred $\mathrm{mm}$ chlorine pressure and $4 \mathrm{~mm}$ trichloroethylene pressure. The results of Mathai and Le Roy ${ }^{2}$ could be due partly to such effects, since they worked at total pressures in the range of $20 \mathrm{~mm}$. 


\section{P. GOLDFINGER}

It may be stated safely that wall reactions do not occur in " conditioned" reaction cells at higher pressures, and that their influence on the quoted values of rate constants is negligible.

In equations (i), (ii) and (iii) the $\mathrm{Cl}+\mathrm{Cl}$ reaction has been neglected. Dainton and co-workers ${ }^{22}$ as well as Mathai and Le Roy ${ }^{2}$ claim, however, to have observed this reaction in the above-mentioned experimental conditions in the photochlorination of trichloroethylene and methyl chloride. In that case equation (iii) should be rewritten as:

$$
\frac{I_{\mathrm{a}}\left(\mathrm{Cl}_{2}\right)}{v^{2}}=\frac{k_{8}}{k_{3}^{2}}+\frac{k_{7}\left[k_{4}+k_{3}\left(\mathrm{Cl}_{2}\right)\right]}{k_{3}^{2} k_{2}\left(\mathrm{C}_{2} \mathrm{HCl}_{3}\right)}+\frac{k_{6}(\mathrm{M})}{k_{3}^{2}}\left[\frac{k_{4}+k_{3}\left(\mathrm{Cl}_{2}\right)}{k_{2}\left(\mathrm{C}_{2} \mathrm{HCl}_{3}\right)}\right]^{2}
$$

which, however, does not include a term for the wall reaction; this is, however, not important for the present argument. In fact, whatever other reactions may occur, the third term of (viii) can be observed only if it is of the same order or larger than the second: $k_{6}(\mathrm{M})\left[k_{4}+k_{3}\left(\mathrm{Cl}_{2}\right)\right] / k_{2} \mathrm{C}_{2} \mathrm{Cl}_{4} \geqslant k_{7}$. Using the data given for $k_{6}, k_{3}$ and $k_{2}$ and considering that $k_{4}$ is negligible ${ }^{23}$ one finds that $k_{7} \leqslant 3 \times 10^{7}$. Now $k_{7}$ has been estimated ${ }^{23}$ to be about $1.5 \times 10^{11 *}$; further, quite a number of $k_{7}$ values seem to lie in this region ${ }^{12}$ and it is difficult to believe that an atom + free radical reaction, which can lead to addition, should be 5000 times slower. A very similar situation arises in a discussion of Le Roy and Mathai's results.

It must of course be emphasized here that it is not claimed that in these cases the $\mathrm{Cl}+\mathrm{Cl}$ recombination has not been observed. What $\mathrm{I}$ am trying to point out is this. If in any mechanism a certain reaction step is assumed and one tries to measure it, this means automatically that some other steps must be measured simultaneously or that an upper limit for the other rate constant can be given. In fact, a thorough kinetic analysis permits one to obtain valuable and precise information about measured reaction steps; it also necessarily gives further information about steps which are comparatively too slow to be measured. This information is of course not accurate; it is, however, not without value. As to the case mentioned here the discussion must remain open.

If the rate constants given recently ${ }^{12}$ are accepted the only case in which the $\mathrm{Cl}+\mathrm{Cl}$ step should be observed readily is in the photochlorination of ethylene. Of course, due to the subsequent reaction of dichloroethane, this may be quite a complicated reaction, similar to that of methane, methyl chloride, etc. This is now being investigated at Brussels $\uparrow$. In order to study such complicated reactions an experimental set-up has been developed by Huybrechts and Verbeke ${ }^{24}$; this comprises a reaction cell, with a pin-hole leak, which is placed inside a mass spectrometer. A minute fraction of the reacting mixture enters the ionizing chamber of the mass spectrometer. This device permits one to perform photochemical reactions near atmospheric pressure, to perform an analysis with a sensitivity of $1 / 10^{5}$ at a rate of 200 peaks per second and, thus, to follow the rate of appearance and disappearance of numerous components in a reacting mixture (Figure 9).

(c) When a chlorine atom adds to a double bond, 17 to $24 \mathrm{kcal} \mathrm{mole}^{-1}$ are liberated; this energy remains in the newly formed free radical, probably

* Note added in proof: In the meantime, $k_{7}=8 \times 10^{10}$ has been measured ${ }^{44}$.

$\dagger$ Note aa'ded in proof: The chlorination of carbon monoxide at about $500^{\circ} \mathrm{K}$ has proved to be a more favourable case. Values of about $10^{10} 1^{2}$. mole ${ }^{-2} \mathrm{sec}^{-1}$ have been found for the reaction $\mathrm{Cl}+\mathrm{Cl}+\mathrm{Cl}_{2}{ }^{45}$. 


\section{REACTIONS OF HALOGEN ATOMS}

as vibrational energy, until it is dissipated by collisions with other molecules. Ayscough et al. ${ }^{22}$ have studied the chlorine sensitized conversion of cis to trans 1,2-dichloroethylene and have explained the mechanism of this

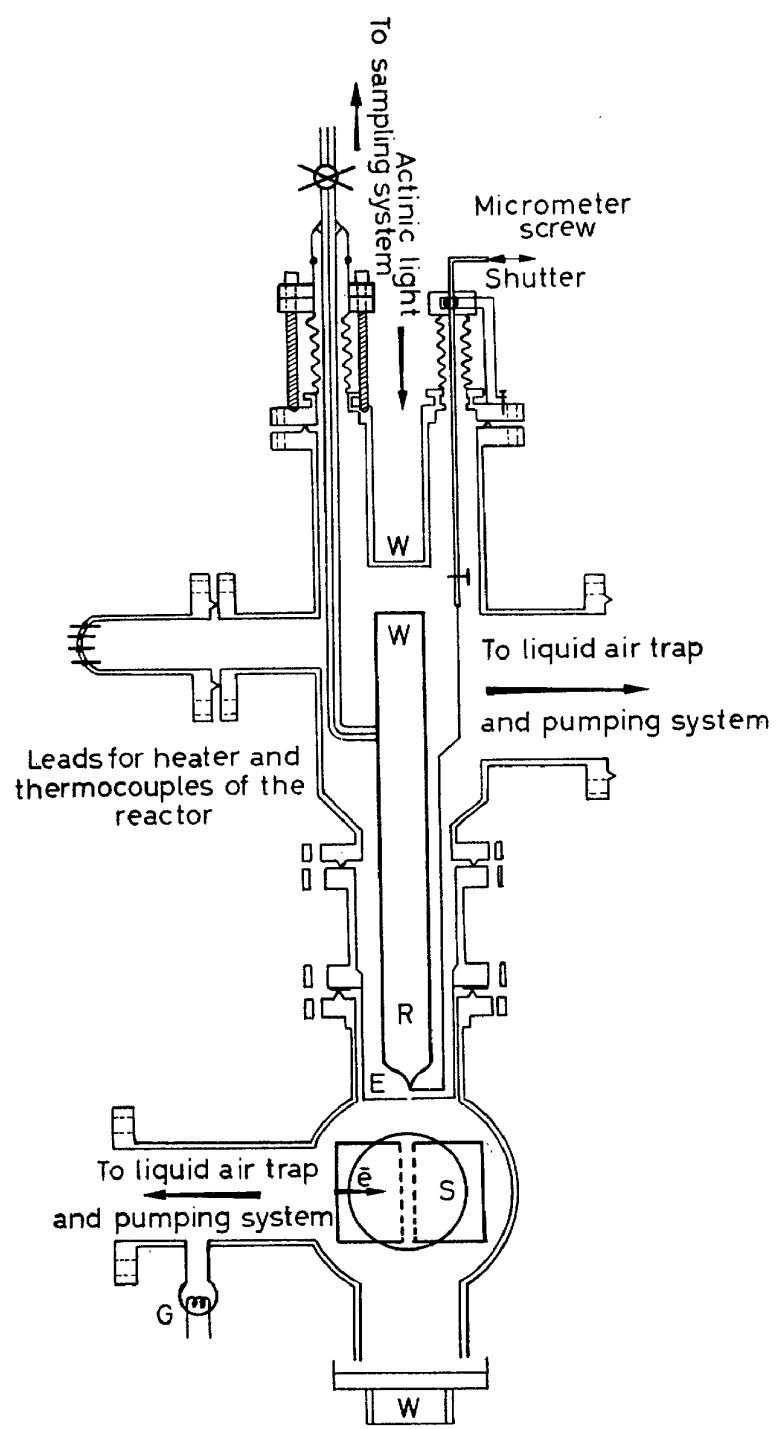

Figure 9. Mass spectrometer for studying photochemical reactions; reactor R, plane parallel windows for illumination $\mathrm{W}$ and leak and slits $\mathrm{E}$ for sampling into ionization chamber of mass spectrometer (Reproduced by permission of the Editor from Advances in Mass Spectrometry, Pergamon Press Ltd. (1962))

reaction in terms of an activated radical $\mathrm{ACl}^{*}$ which decomposes according to three possibilities: a monomolecular reaction, a collision induced decomposition or a reaction with molecular chlorine yielding a trichloryl 


\section{P. GOLDFINGER}

radical. Wijnen ${ }^{25}$ has also observed conversion reactions, which he explains on a similar basis.

On the other hand no difference could be observed between the free radicals, pentachloroethane, formed in process $(2)$ or $\left(2^{\prime}\right)$. Further mixtures of trichloroethylene and the two tetrachloroethanes have been studied. In such mixtures two over-all processes are competing:

and

$$
\mathrm{C}_{2} \mathrm{HCl}_{3}+\mathrm{Cl}_{2} \longrightarrow \mathrm{C}_{2} \mathrm{HCl}_{5}
$$

$$
\mathrm{C}_{2} \mathrm{H}_{2} \mathrm{Cl}_{4} \longrightarrow \mathrm{C}_{2} \mathrm{HCl}_{3}+\mathrm{HCl}
$$

One can easily show that for adequate pressure ratios of the reagents no pressure change will occur; this is the case for

$$
\left(\mathrm{C}_{2} \mathrm{HCl}_{3}\right)\left(\mathrm{Cl}_{2}\right) /\left(\mathrm{C}_{2} \mathrm{H}_{2} \mathrm{Cl}_{4}\right)=\left(k_{2}^{\prime} k_{4} / k_{2} k_{3}\right) \frac{1+k_{3}\left(\mathrm{Cl}_{2}\right) / k_{4}}{1+k_{3}^{\prime}\left(\mathrm{Cl}_{2}\right) / k_{4}^{\prime}}
$$

If the free radical formed from the ethane by hydrogen abstraction is identical with that formed from the ethylene by chlorine addition, then the ratio on the left hand side of equation (ix) will not depend on the chlorine pressure;

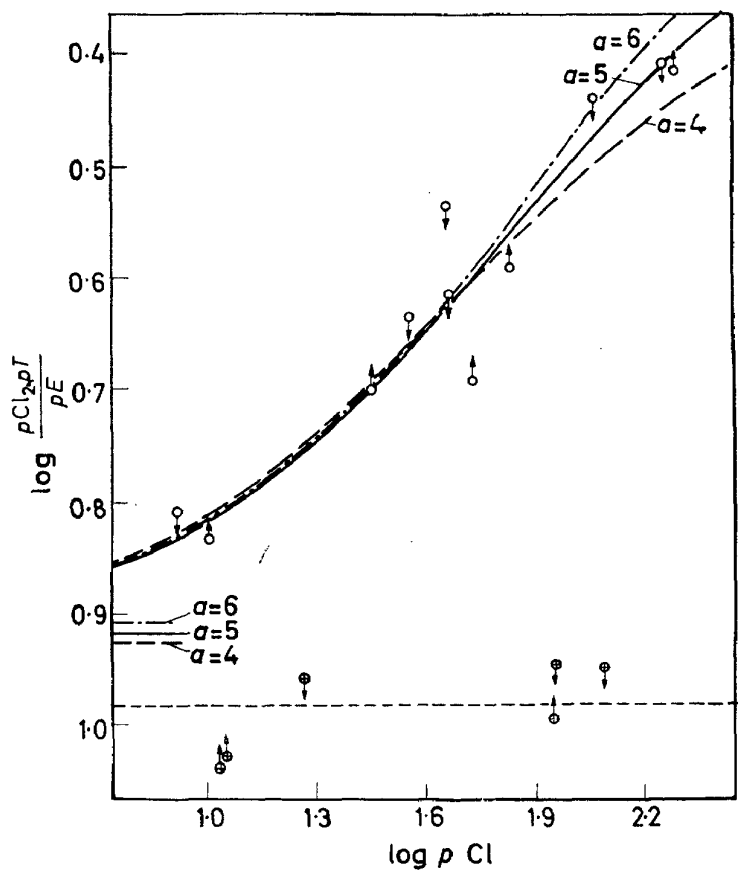

Figure 10. Plot of equation (ix) showing identity of the radical obtained by $\mathrm{Cl}$ addition to $\mathrm{C}_{2} \mathrm{HCl}_{3}$ and $\mathrm{H}$ abstraction from $1,1,1,2-\mathrm{C}_{2} \mathrm{H}_{2} \mathrm{Cl}_{4}$; the $1,1,2,2-\mathrm{C}_{2} \mathrm{HCl}_{4}$ radical is, therefore, in both cases a thermally stabilized and not a vibrationally activated hot radical

if the reverse is the case it will be a so-called homographic function of this pressure (the constants with primes refer to the ethane and those without primes to the ethylene). As shown in Figure 10, the former is the case for 1,1,2,2-tetrachloroethane and the latter for the 1,1,1,2-derivative. This 


\section{REACTIONS OF HALOGEN ATOMS}

confirms the above-mentioned finding about the constitution of this radical and simultaneously proves that the "hot radical" is not observed here. The activation energy of $k_{2}^{\prime} k_{4} / k_{2} k_{3}$ is in agreement with an activation energy of $k_{4}$ of about $18 \mathrm{kcal}$ corresponding to the value of a stabilized radical.

In order to explain this apparent discrepancy, Dainton ${ }^{26}$ has made the following proposal: the more chlorinated a compound is the more uniformly the energy will be distributed between low frequency vibrations and the greater will be the probability of deactivation compared to the probability of decomposition. In that case the hot radical effect is expected to be observed for radicals containing a small number of chlorine atoms: according to the present status of the problem it is observed for the trichloroethyl radical and not for the tetra- and pentachloroethyl radicals. The strongest effect should appear in the case of ethylene. This could be in line with Schumacher's $\mathrm{s}^{27}$ study of this reaction. Similar arguments to those given in relation to the assumed observations of $\mathrm{Cl}-\mathrm{Cl}$ recombinations do not permit us however to accept this interpretation without repetition of Schumacher's measurements with modern techniques. As mentioned already this is being done at present*.

\section{ACTIVATED COMPLEX THEORY}

The activated complex theory has been applied to chlorine atom reactions, e.g. by Fettis, Knox and Trotman-Dickenson ${ }^{3}$ using a rather primitive method. Recently H. S. Johnston ${ }^{5}$ has treated systematically over 60 reactions.

(a) Reactions with activation energy; a Sato ${ }^{28}$ potential energy surface was used for some cases, all reactions were treated by the simpler bondenergy-bond-order (BEBO) method ${ }^{29}$. In those cases in which both methods have been used complete agreement was obtained. Both methods are considered as purely empirical representations of the potential energy surface and both contain only one adjustable parameter.

For the reaction R..H...Cl the adjustable parameter $\Delta=0.25$ in Sato's method and $p=1.07$ in Johnston's BEBO method were chosen so as to get the best fit for the reaction $\mathrm{CH}_{3} \ldots \mathrm{H}$...Cl. For the R...Cl...Cl reactions $p=1.20$ gave the best fit in the middle of the range.

This then permits one to calculate potential energy surfaces and potential energies of activation. Detailed calculations, taking into account vibration frequencies and other properties of the reactants and carrying out full vibrational analysis for the complex, were done for the hydrogen transfer reactions $\mathrm{CH}_{3} . . \mathrm{H}$..Gl, to $\mathrm{CGl}_{3} . . \mathrm{H}$.. $\mathrm{Cl}$ and $\mathrm{CD}_{3}$. . D..Cl, and $\mathrm{CGl}_{3}$...D..Cl and for attack on $\mathrm{Cl}_{2}$ by $\mathrm{CH}_{3}, \mathrm{CH}_{2} \mathrm{Cl}, \mathrm{CHCl}_{2}$ and $\mathrm{CCL}_{3}$. Distances, force constants and frequencies were evaluated for the complex. Tunnelling corrections were made.

It must be emphasized that in these methods, once a parameter $\Delta$ or $p$ has been chosen, no further adjustments can be made in calculating either activation energies or frequency factors. Therefore, the agreement between calculated and observed $A$-factors (Table 1 ) for both the R...H...Cl and

* Note added in proof: Good evidence has been now obtained that the primary activated addition product of a chlorine atom to ethylene does not decompose or react prior to deactivation in the pressure range around 50 to $200 \mathrm{~mm} \mathrm{Hg}^{46}$. 


\section{P. GOLDFINGER}

the R...Cl...Cl reactions is considered as extremely gratifying. Also the calculated isotope effect is in qualitative agreement with Newton and Rollefson' ${ }^{31}$ rather crude experiments with chloroform; experiments are being performed now at Brussels to check these results and to extend them to the case of the methanes*.

Table 1. Reactions with activation energy

\begin{tabular}{|c|c|c|c|c|}
\hline \multicolumn{2}{|c|}{$\mathrm{CH}_{3} \ldots \mathrm{H} \ldots \mathrm{Cl}$} & $\mathrm{CH}_{2} \mathrm{Cl} \ldots \mathrm{H} \ldots \mathrm{Cl}$ & $\mathrm{CHCl}_{2} \ldots \mathrm{H} \ldots \mathrm{CI}$ & $\mathrm{CGl}_{3} \ldots \mathrm{H} \ldots \mathrm{Cl}$ \\
\hline $\begin{array}{rc}E & c \\
\log A & c \\
& 0\end{array}$ & $\begin{array}{r}3 \cdot 6 \\
3 \cdot 9 \\
10 \cdot 5 \\
10 \cdot 7\end{array}$ & $\begin{array}{r}1 \cdot 6 \\
3 \cdot 1 \\
10 \cdot 4 \\
10 \cdot 5\end{array}$ & $\begin{array}{r}0 \cdot 9 \\
3 \cdot 1 \\
10 \cdot 1 \\
10 \cdot 4\end{array}$ & $\begin{array}{r}0 \cdot 8 \\
3 \cdot 3 \\
9 \cdot 8 \\
10 \cdot 2\end{array}$ \\
\hline $\mathrm{CH}$ & $\mathrm{Gl} \ldots \mathrm{Gl}$ & $\mathrm{CH}_{2} \mathrm{Cl} \ldots \mathrm{Cl} \ldots \mathrm{Cl}$ & $\mathrm{CHCl}_{2} \ldots \mathrm{Cl} \ldots \mathrm{Cl}$ & $\mathrm{CGl}_{3} \ldots \mathrm{Cl} \ldots \mathrm{Cl}$ \\
\hline 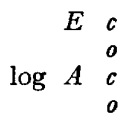 & $\begin{array}{r}4 \cdot 1 \\
2 \cdot 3 \\
10 \cdot 0 \\
9 \cdot 9\end{array}$ & $\begin{array}{l}4 \cdot 5 \\
3 \cdot 0 \\
9 \cdot 6 \\
9 \cdot 6\end{array}$ & $\begin{array}{l}4 \cdot 6 \\
4 \cdot 0 \\
9 \cdot 4 \\
9 \cdot 0\end{array}$ & $\begin{array}{l}5 \cdot 1 \\
6 \cdot 0 \\
9 \cdot 1 \\
8 \cdot 7\end{array}$ \\
\hline
\end{tabular}

\footnotetext{
$E_{\mathrm{a}}=$ Activation energy kcal mole $\mathrm{k}^{-1}$

$A=$ Frequency factor in $1 . \mathrm{mole}^{-1} \mathrm{sec}^{-1}$

$c=$ Calculated

0 Observed
}

For the R. Cl. .Cl reactions the agreement for the activation energies is not good (see Table 1); the trend in activation energies appears, however, to be in agreement with observation. Further, it must be recalled that in many instances these measurements are extremely difficult because of the complex reaction mechanism mentioned above.

It is important to recall that the potential energy surfaces yield the potential energy of activation $V_{a}$ which differs from the empirical activation energy $E_{\mathrm{a}}$; for $\mathrm{RH}+\mathrm{Cl}, V_{\mathrm{a}}<E_{\mathrm{a}}$, for $\mathrm{R}+\mathrm{Cl}_{2}$ the reverse is the case. Thus, the very low activation energies of $1 \mathrm{kcal}$ for ethyl, chloroethyl and dichloroethyl radicals with molecular chlorine are questionable and would merit further experimental work.

The most important disagreement lies in the activation energies in the series of hydrogen abstraction reactions from methane to chloroform. This is in sharp contrast to the series methane, ethane, propane in which excellent agreement is obtained between calculated and observed activation energies for a variation of $\mathrm{C}-\mathrm{H}$ bond dissociation energy from 102 to $93 \mathrm{kcal}$ mole ${ }^{-1}$.

It is natural to try to explain the disagreement for the series of chlorinated methanes in terms of non-bonding interactions between chlorine atoms. An evaluation by means of a Lennard-Jones 6-12 function using the "Van der Waals-radius" and the polarizability of chlorine shows, however, that for the dimensions predicted by the Sato or BEBO method the Cl...Cl interactions are on the attractive and not on the repulsive side.

It has been proposed by Johnston to seek the explanation in a dynamic effect: as a chlorine atom approaches a methyl chloride molecule at a

* Note added in proof: These have confirmed theoretical predictions ${ }^{47}$. 


\section{REACTIONS OF HALOGEN ATOMS}

relatively great distance of 6 or $8 \AA$, the $\mathrm{Cl}$...Cl dispersion forces are much greater than the $\mathrm{CI}$...H dispersion or even the $\mathrm{Cl}$.. H bonding forces. Therefore, unless the approaching atom has a relatively high kinetic energy a complex $\mathrm{H}_{3} \mathrm{C}-\mathrm{Cl}$... Gl forms instead of the "activated hydrogen atom transfer complex " $\mathrm{H}_{2} \mathrm{ClC}-\mathrm{H}$. . Cl.

(b) Reactions of zero activation energy were treated by Gorin's model ${ }^{32}$ and the results are summarized in Table 2. Apparently there is a certain

Table 2. Reactions with zero activation energy

\begin{tabular}{|c|c|c|c|c|c|c|c|c|}
\hline & \multicolumn{2}{|c|}{$\log k$} & \multicolumn{3}{|c|}{$\log k$} & & \multicolumn{2}{|c|}{$\log k$} \\
\hline & $c$ & 0 & & $c$ & $o$ & & $c$ & 0 \\
\hline $\begin{array}{l}2 \mathrm{CH}_{3} \\
2 \mathrm{CH}_{2} \mathrm{Cl} \\
2 \mathrm{CHCl}_{2} \\
2 \mathrm{CCl}_{3} \\
2 \mathrm{C}_{2} \mathrm{H}_{5} \\
2 \mathrm{C}_{2} \mathrm{H}_{4} \mathrm{Cl}\end{array}$ & $\begin{array}{l}10 \cdot 8 \\
10 \cdot 7 \\
10 \cdot 7 \\
10 \cdot 7 \\
10 \cdot 8 \\
10 \cdot 7\end{array}$ & $\begin{array}{r}10 \cdot 5 \\
9 \cdot 6 \\
9 \cdot 4 \\
8 \cdot 8 \\
10 \cdot 5 \\
10 \cdot 1\end{array}$ & $\begin{array}{l}\mathrm{CH}_{3}+\mathrm{Cl} \\
\mathrm{CH}_{2} \mathrm{Cl}+\mathrm{Cl} \\
\mathrm{CHCl}_{2}+\mathrm{Cl} \\
\mathrm{CCl}_{3}+\mathrm{Cl} \\
\mathrm{C}_{2} \mathrm{H}_{5}+\mathrm{Cl} \\
\mathrm{C}_{2} \mathrm{H}_{4} \mathrm{Cl}+\mathrm{Cl}\end{array}$ & $\begin{array}{l}10 \cdot 7 \\
10 \cdot 6 \\
10 \cdot 6 \\
10 \cdot 7 \\
10 \cdot 7 \\
10 \cdot 7\end{array}$ & $\begin{array}{l}11 \cdot 6 \\
11 \cdot 4 \\
11 \cdot 4 \\
11 \cdot 4 \\
11 \cdot 3 \\
11 \cdot 3\end{array}$ & $\begin{array}{l}\mathrm{C}_{2} \mathrm{H}_{4}+\mathrm{Cl} \\
\mathrm{C}_{2} \mathrm{H}_{3} \mathrm{Cl}+\mathrm{Cl} \\
\mathrm{C}_{2} \mathrm{HCl}_{3}+\mathrm{Cl} \\
\mathrm{C}_{2} \mathrm{Cl}_{4}+\mathrm{Cl}\end{array}$ & $\begin{array}{l}11 \cdot 3 \\
11 \cdot 2 \\
11 \cdot 3 \\
11 \cdot 3\end{array}$ & $\begin{array}{r}10 \cdot 2 \\
10 \cdot 2 \\
10 \cdot 0 \\
9 \cdot 6\end{array}$ \\
\hline $2 \mathrm{C}_{2} \mathrm{Cl}_{5}$ & $10 \cdot 7$ & $8 \cdot 7$ & $\mathrm{C}_{2} \mathrm{Cl}_{5}+\mathrm{CI}$ & $10 \cdot 7$ & $11 \cdot 3$ & & & \\
\hline
\end{tabular}

$k=$ Rate constant in $1 . \mathrm{mol}^{-1} \mathrm{sec}^{-1}$.

$c=$ Calculated

$o=$ Observed

agreement concerning order of magnitude especially for radical + chlorine atom reactions. The observed decrease by a factor of about 50 for the radical recombination rate from methyl to trichloromethyl and from ethyl to pentachloroethyl does not appear in the calculated rates. Also for the atom addition to a double bond a decrease by a factor of four is observed from ethylene to tetrachloroethylene, whereas no variation is obtained for the calculated constants. No explanation is found for the highly specific "symmetric " addition of a chlorine atom to trichloroethylene.

A deeper analysis of the theory has been carried out by evaluating the relative rate and the critical diameter for each rotational quantum state of the rotating complex. As a test the case of almost perfect agreement $\mathrm{CH}_{3}+$ $\mathrm{CH}_{3}$ and the case of worst disagreement $\mathrm{CCl}_{3}+\mathrm{CCl}_{3}$ have been treated. It appears that the internal inconsistency is nearly as bad in the former as in the latter case.

\section{GONCLUSIONS}

The photochlorination studies at Brussels were started about 12 years ago with Gosselain and Martin ${ }^{33}$. The question of interest at that time, concerning competition between addition and substitution was solved by applying a general mechanism. The ratio of the rates is given by:

$$
v_{\mathrm{s}} / v_{\mathrm{a}}=\left(k_{2}^{\prime}(\mathrm{S}) / k_{2}(\mathrm{~A})\right)\left(1+k_{4} / k_{3}\left(\mathrm{Cl}_{2}\right)\right) \quad \text {. }
$$

as shown in Figure 11. Substitution is favoured not so much by conditions which favour hydrogen abstraction, as by those which favour instability of the radical formed by addition to a double bond. This explains the action 


\section{P. GOLDFINGER}

of many halogenating agents $\mathrm{s}^{35-37}$ and permits one to dismiss Walling's criticism $^{38}$.

The heuristic value of the mechanism has appeared in the course of time. It permitted the very complete solution of the $\mathrm{C}_{2} \mathrm{Cl}_{4}-\mathrm{C}_{2} \mathrm{Cl}_{5} \mathrm{H}-\mathrm{Cl}_{2}$ system ${ }^{18,38}$. It led to an understanding of anomalous reaction orders, to an improvement in the methods of kinetic analysis, and to the submission of the latter to

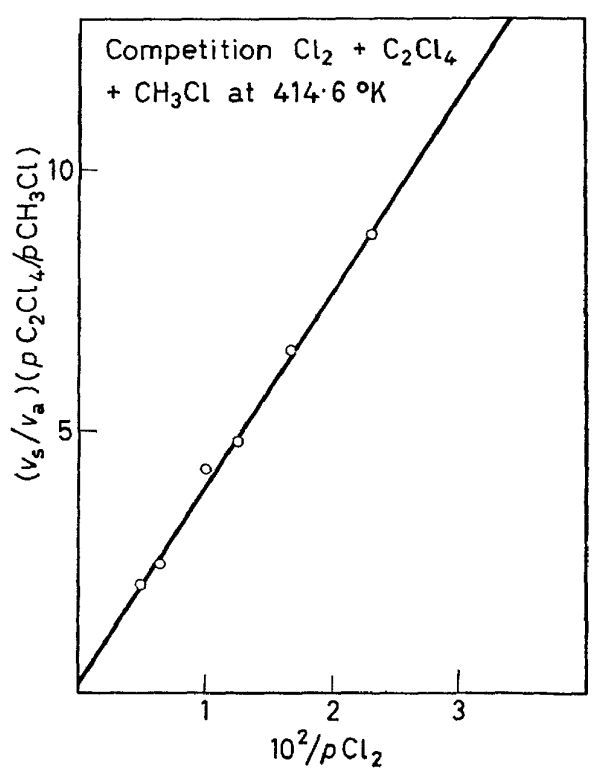

Figure 11. Plot of a competitive reaction according to equation (x) (Reproduced by permission of the Council of the Faraday Society from Trans. Faraday Soc. 57, 2213 (1961))

severe tests. It led to a clearer understanding of certain cases of inhibition ${ }^{7,18}$, auto-inhibition ${ }^{12}$ (equation (iv)) and related phenomena than was possible from other kinetic studies: in many cases now all elementary steps are known, all intermediate and final products have been identified, and the corresponding rate constants have been measured. It would be quite important to develop quite general schemes for inhibition reactions including those given here as well as the recent considerations of Eyring ${ }^{39}$, Laidler ${ }^{40}$ and co-workers.

The pyrolysis of chlorinated hydrocarbons which were studied a few years ago by Barton, Howlett ${ }^{41}$ and co-workers, and which have been partly re-interpreted ${ }^{42}$, are in complete agreement with the proposed mechanism and the measured rate constants.

Besides these problems which arose in the course of time and have been solved, others have been known for a more-or-less long time and cannot be considered as settled. Some of these are: the ratio of addition to dismutation in radical-radical and radical-atom reactions of highly chlorinated radicals; the nature and properties of the primary activated addition product of a chlorine atom to an ethylene; the chlorine atom recombination.

It seems that photochemical halogenation reactions are relatively simple. Nevertheless, it appeared that in the simplest systems competing steps or other 


\section{REACTIONS OF HALOGEN ATOMS}

complicating factors occur: addition-dehydrochlorination, consecutive reactions, two chain-breaking steps and others. The cross checks of rate constants applied systematically in this research and the accurate measurements of rates during an important part of the reaction, instead of the much less tedious integration methods or measurements of so-called initial rates, have shown that quite important errors and ambiguities may result in kinetic studies. Therefore, great emphasis has been directed to this point.

The opinions stated 8 or 10 years ago by Adam and Gosselain ${ }^{\mathbf{4 3}}$ needed only one drastic revision, even though a number of minor corrections have become necessary as experimental accuracy has been improved. It had been assumed that in considering a set of reactions from non-chlorinated to perchlorinated hydrocarbons a considerable decrease of frequency factors should be observed. This was based on an over-simplified model of the activated complex. In fact there is a small decrease for $k_{2}, k_{3}, k_{4}^{\prime}$ and $k_{8}$. The more refined calculations permit one now to understand some of the trends in frequency factors and activation energies. But for many finer trends it appears that the theory of the activated complex in its present form is inadequate. Whether this resides in inadequacies of the theory itself or of the necessary tool for this theory, the description of the activated state is not possible to assess.

We had often thought that we were approaching the conclusion of our photochlorination studies.

I do not believe this any more.

Thanks are due to Professor H. S. Fohnston who, during his recent stay at Brussels helped us greatly to understand the theoretical aspects of these problems.

I wish to thank my collaborators, G. Chiltz, G. Martens, and G. Huybrechts, for their enthusiastic and competent co-operation; a great part of the experimental results and of the discussion presented here is their work or due to our joint effort.

This research has been sponsored, in part, by the Office, Chief of Research and Development, U.S. Department of Army, through its European Office.

Financial support from Centre National Belge de Chimie Physique Moléculaire and Institut pour l'Encouragement de la Recherche Scientifique dans l'Industrie et l'Agriculture (Brussels, Belgium) is gratefully acknowledged.

This manuscript was completed during the tenure and thanks to the facilities offered as a Visiting Scientist at the National Research Council of Canada.

\section{References}

1 F. S. Dainton, D. A. Lomax, and M. Weston. Trans. Faraday Soc. 53, 460 (1957).

${ }^{2}$ D. J. Le Roy and K. G. Mathai. Can. J. Chem. 40, 189 (1962).

${ }^{3}$ G. C. Fettis, J. H. Knox, and A. F. Trotman-Dickenson. Can. 7. Chem. 38, 1643 (1956);

A. F. Trotman-Dickenson and J. H. Knox. F. Phys. Chem. 60, 1367 (1956);

J. H. Knox. Trans. Faraday Soc. 58, 275 (1962).

${ }^{4}$ K. S. Pitzer. 7. Am. Chem. Soc. 79, 1804 (1957).

5 H. S. Johnston and P. Goldfinger. 7. Chem. Phys. August (1956).

${ }^{6}$ P. Goldfinger, M. Niclause, and M. Letort. Vol. Comm. V. Henri, Liége (1948).

7 G. Chiltz, A. M. Mahieu, and G. Martens. Bull. soc. chim. Belges 67, 33 (1958).

${ }^{8}$ S. Benson. 7. Chem. Phys. 20, 1605 (1952).

${ }^{9}$ J. Adam, S. Dusoleil, and P. Goldfinger. Bull. soc. chim. Belges 65, 942 (1956).

10 M. Letort. F. chim. phys. 54, 206 (1937).

$11 \mathrm{~J}$. Adam and P. Goldfinger. Bull. soc. chim. Belges 65, 561 (1956). 


\section{P. GOLDFINGER}

${ }^{12}$ R. Eckling, P. Goldfinger, G. Huybrechts, G. Martens, L. Meyers, and S. Smoes. Chem. Ber. 93, 3014 (1960).

${ }^{13}$ J. Draper. Phil. Mag. 25, 1 (1844); 26, 476 (1845).

$14 \mathrm{~S}$. Benson. 7. Chem. Phys. 22, 46 (1954).

${ }_{15}$ D. J. Wilson. F. Phys. Chem. 62, 653 (1958).

16 P. Goldlfinger, G. Huybrechts, Mme. A. M. Mahieu-Van der Auwera, and D. Van der Auwera. 7. Phys. Chem. 64, 468 (1960).

17 W. G. Burns and F. S. Dainton. Trans. Faraday Soc. 48, 39 (1952).

${ }_{18}$ P. Goldfinger, G. Huybrechts, and G. Martens. Trans. Faraday Soc. 57, 2210 (1961).

${ }^{10}$ G. K. Rollefson. The Photochemistry of Halogens Herman et Cie, Paris (1938).

${ }^{20}$ G. Porter and J. A. Smith. Proc. Roy. Soc. A261, 28 (1961).

${ }^{21}$ W. A. Noyes Jr. and P. A. Leighton. The Photochemistry of Gases Reinhold, N.Y. (1941).

${ }_{22}$ P. B. Ayscough, A. J. Cocker, F. S. Dainton, S. Hirst, D. A. Lomax, and M. Weston. XVIIIth Intern. Congr. of Pure and Appl. Chem. Montreal, August (1961); P. B. Ayscough, A. J. Cocker, and F. S. Dainton. Trans. Faraday. Soc. 58, 287 (1962).

${ }^{23}$ G. Huybrechts. Mémoire de Licence Faculté des Sciences, Université Libre de Bruxelles; G. Chiltz, R. Deltour, P. Goldfinger, G. Huybrechts, and D. van der Auwera. Final Technical Report to Office Chief of Research and Development U.S. Department of Army, European Office (1958).

24 P. Goldfinger, G. Huybrechts, and G. Verbeke. Mass Spectrometry Conference (Oxford), September (1961).

${ }^{25}$ M. J. H. Wijnen. Private communication.

${ }^{26}$ P. B. Ayscough, A. J. Cocker, F. S. Dainton, and S. Hirst. Trans. Faraday Soc. 58, 318 (1962).

${ }^{27}$ R. Schmitz, H. J. Schumacher, and A. Jäger. Z. physik. Chem. (Leipzig), B51, 281 (1942).

${ }^{28}$ S. Sato. F. Chem. Phys. 23, 592, 2465 (1955); see also R. Weston. 7. Chem. Phys. 31, 892 (1959).

${ }^{29}$ H. S. Johnston. Advances in Chem. Phys. 3, 131 (1960).

${ }^{30} \mathrm{~J}$. H. Knox. Private communication.

31 T. W. Newton and G. K. Rollefson. F. Chem. Phys. 17, 718 (1949).

${ }^{32}$ E. Gorin. Acta. Physicochim. U.R.S.S. 6, 691 (1938).

33 P. Gold.finger, P. A. Gosselain, and R. H. Martin. Nature 168, 30 (1951); J. Adam, P. Goldfinger, and P. A. Gosselain. Nature 171, 704 (1952).

${ }_{34}$ J. Adam, P. Goldfinger, and P. A. Gosselain. Bull. soc. chim. Belges 65, 523 (1956).

${ }^{35}$ P. C. Anson, P. S. Fredricks, and J. M. Tedder. 7. Chem. Soc., 1959, 918;

P. S. Fredricks and J. M. Tedder. F. Chem. Soc. 1960, 144.

${ }^{36}$ F. L. J. Sixma and R. H. Riem. Koninkl. Ned. Akad. Wetenschap. Proc. B61, 183 (1958).

${ }^{37}$ C. Walling. Free Radicals in Solutions John Wiley \& Sons Inc., New York (1957).

${ }^{38}$ S. Dusoleil, P. Goldfinger, Mme. A. M. Mahieu-van der Auwera, G. Martens, and D. van der Auwera. Trans. Faraday Soc. 57, 2197 (1961).

${ }^{39}$ H. Eyring, K. Yang, and T. Ree. 18th Intern. Congr. of Pure and Appl. Chem. Montreal, August (1961).

${ }^{40}$ B. W. Wojciechowski and K. J. Laidler. Can. F. Chem. 38, 1027 (1960).

41 K. E. Howlett. Trans. Faraday Soc. 48, 35 (1952).

42 P. Goldlfinger and G. Martens. Trans. Faraday Soc. 57, 2220 (1961).

${ }^{43}$ J. Adarn, P. Goldfinger, and P. A. Gosselain. Bull. soc. chim. Belges 65, 533 (1956).

${ }^{44}$ G. Huybrechts, L. Meyers, and G. Verbeke. Trans. Faraday Soc. 58, 1128 (1962).

${ }^{45}$ G. Chiltz, R. Eckling, P. Goldfinger, G. Huybrechts, G. Martens, and G. Simoens. Paper presented at the Photochemistry Meeting, Brussels, June (1962).

${ }^{46}$ G. Huybrechts, G. Martens, T. Montenez, and A. Verhasselt. To be published.

${ }^{47}$ G. Chiltz, R. Eckling, P. Goldfinger, G. Huybrechts, H. S. Johnston, L. Meyers, and G. Verbeke. Submitted for publication in 7. Chem. Phys. 